Huiskes, V.J.B., Cramer-van der Welle, C., Ende, C.H.M. van den, Dijk, L. van, Bos, J.M., Kramers, C., Bemt, B.J.F. van den. Communication about Drug-Related Problems (DRPs) during patients' visits to Dutch physicians and pharmacies. Health Communication: 2020, 35(2), p. 201-208

Postprint version

Journal website

Pubmed link

DOI
: $\quad$ https://www.tandfonline.com/doi/abs/10.1080/10410236.2018.155130 1?journalCode=hhth20

: https://www.ncbi.nlm.nih.gov/pubmed/?term=30526088

: $10.1080 / 10410236.2018 .1551301$

This is a Nivel certified Post Print, more info at nivel.nl

\title{
Communication about Drug-Related Problems (DRPs) during Patients' Visits to Dutch Physicians and Pharmacies
}

\author{
Victor J. B. Huiskes ${ }^{a,}{ }^{*}$, Christine M. Cramer-van der Welle ${ }^{b,}{ }^{*}$, Cornelia H. M. \\ van den Ende ${ }^{c}$, Liset van Dijk ${ }^{d}$, Jacqueline M. Bos ${ }^{b}$, Cornelis Kramers $^{b, e}$, and \\ Bart J. F. van den Bemt ${ }^{a, f, g}$

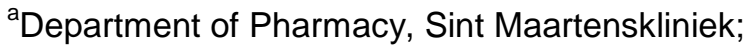 \\ ${ }^{b}$ Department of Clinical Pharmacy, Canisius-Wilhelmina Hospital; \\ 'Department of Rheumatology, Sint Maartenskliniek; \\ ${ }^{d}$ NIVEL, Netherlands Institute for Health Services Research; \\ ${ }^{e}$ Department of Pharmacology-Toxicology and Internal Medicine, Radboud University Medical \\ Center; \\ fDepartment of Pharmacy, Radboud University Medical Center; \\ ${ }^{9}$ Department of Clinical Pharmacy and Toxicology, Maastricht University Medical Center +
}

\begin{abstract}
The objective of this study is to assess the frequency and type of drug-related problems (DRPs) (1) raised and discussed (2) raised but not discussed or (3) not raised during patients' visits to healthcare practitioners (HCPs). In this cross-sectional study in Dutch outpatient clinics, GP practices and pharmacies, verbal cues from patients and HCPs indicating DRPs were inventoried by an observer during visits. It was also observed whether raised DRPs were discussed between patient and HCP. Post-encounter interviews (HCPs) were conducted and post-encounter questionnaires (patient) were distributed to identify DRPs not raised. In total, 431 patients were observed during a single visit. In $42.2 \%$ of these visits, 311 DRPs were raised (weighted mean (SD) 0.7 ( \pm 1.1$)$ DRP/patient). Of these 311 DRPs, $82.0 \%$ were discussed between HCP and patient. HCPs did not raise existing DRPs in $3.9 \%$ of the 431 visits; in $6.3 \%$ of the 176 questionnaires the patient reported an existing DRP that had not been raised. In conclusion, almost one in six of the DRPs raised during visits are not discussed between HCP and patient. Furthermore, existing DRPs are not even raised in $4-6 \%$ of the visits. HCPs and patients should be aware that, although patients often have DRPs, these are not always discussed or not even raised during patients' visits.
\end{abstract}


Huiskes, V.J.B., Cramer-van der Welle, C., Ende, C.H.M. van den, Dijk, L. van, Bos, J.M., Kramers, C., Bemt, B.J.F. van den. Communication about Drug-Related Problems (DRPs) during patients' visits to Dutch physicians and pharmacies. Health Communication: 2020, 35(2), p. 201-208

Medications are involved in $80 \%$ of all medical treatments (Patient-Centered Primary Care Collaborative, 2016 Patient-Centered Primary Care Collaborative. (2016). PCPCC medication management task force. integrating comprehensive medication management to optimize patient outcomes. Retrieved from www.pcpcc.org/sites/default/files/media/medmanagement.pdf ). Although medications usually improve a patient's quality and/or duration of life, they can also cause considerable harm. During medication reviews an average of four drug-related problems (DRPs) are identified per patient with polypharmacy. A drug-related problem is defined as an event or circumstance involving drug therapy that actually or potentially interferes with desired health outcomes (Pharmaceutical Care Network Europe Foundation, 2016 Pharmaceutical Care Network Europe Foundation. (2016). The PCNE classification V 6.2. Retrieved from www.pcne.org/upload/files/11_PCNE_classification_V6-2.pdf ). DRPs can lead to serious consequences. The HARM-study (Hospital Admissions Related to Medication), for example, illustrated that $5.6 \%$ of the unplanned hospital admissions are directly drug-related. Almost half of these drugrelated admissions (46.5\%) could have been avoided (Leendertse, Egberts, Stoker, \& van den Bemt, 2008 Leendertse, A. J., Egberts, A. C., Stoker, L. J., \& van den Bemt, P. M. (2008). Frequency of and risk factors for preventable medication-related hospital admissions in the Netherlands. Archives of Internal Medicine, 168(17), 1890-1896. doi:10.1001/archinternmed.2008.3 , ).

Suboptimal communication between HCPs and patients increases the incidence and negatively influences the management of DRPs (American Pharmacists Association and National Association of Chain Drug Stores Foundation, 2016 American Pharmacists Association and National Association of Chain Drug Stores Foundation. (2016). Medication therapy management in pharmacy practice. Core elements of an MTM service model. Retrieved from

www.pharmacist.com/sites/default/files/files/core_elements_of_an_mtm_practice.pdf ; Howard, Avery, \& Bissell, 2008 Howard, R., Avery, A., \& Bissell, P. (2008). Causes of preventable drug-related hospital admissions: A qualitative study. Quality \& Safety in Health Care, 17(2), 109-116.

doi:10.1136/qshc.2007.022681, , ). Patients do not always report medication-related symptoms and/or adverse events to physicians, and physicians do not always respond when patients actually report them (Gandhi et al., 2003 Gandhi, T. K., Weingart, S. N., Borus, J., Seger, A. C., Peterson, J., Burdick, E., ... Bates, D. W. (2003). Adverse drug events in ambulatory care. The New England Journal of Medicine, 348(16), 1556-1564. doi:10.1056/NEJMsa020703 ;; Henselmans, Heijmans, Rademakers, \& van Dulmen, 2015 Henselmans, I., Heijmans, M., Rademakers, J., \& van Dulmen, S. (2015).

Participation of chronic patients in medical consultations: Patients' perceived efficacy, barriers and interest in support. Health Expectations, 18(6), 2375-2388. doi:10.1111/hex.12206 , ). Not only do patients not always mention drug-related issues, research has found that adverse events, patients' experiences with their drug use and adherence are often not explored by HCPs during clinical visits (Prins, Schoen, Doggen, van Dijk, \& van Dulmen, 2008 Prins, M., Schoen, T., Doggen, C., van Dijk, L., \& van Dulmen, S. (2008). Het betrekken van het perspectief van patiënt en voorschrijver bij het verbeteren van de communicatie over geneesmiddelen en therapietrouw [Involving the perspective of patient and prescriber in improving communication about medicines and adherence]. Retrieved from www.nivel.nl/sites/default/files/bestanden/NIVW\%2019.pdf ; van Bijnen \& van Dulmen, 2010 van Bijnen, E., \& van Dulmen, S. (2010). Een goed gesprek over geneesmiddelgebruik; determinanten vanuit het perspectief van de voorschrijver [A good converstation about drug use; determinants from the perspective of the prescriber]. Retrieved from www.nivel.nl/sites/default/files/bestanden/Rapport-Geneesmiddelgebruik-2010.pdf ). The need for better communication is also emphasized in several recommendations aiming to optimize the communication with patients about drugs (Australian Commission on Safety and Quality in Health Care, 2016 Australian Commission on Safety and Quality in Health Care. (2016). The OSSIE guide to clinical handover improvement. Retrieved from www.safetyandquality.gov.au/wpcontent/uploads/2012/01/ossie.pdf ; WHO Collaborating Centre for Patient Safety Solutions, 2016 WHO Collaborating Centre for Patient Safety Solutions. (2016). Communication during patient hand- 
Huiskes, V.J.B., Cramer-van der Welle, C., Ende, C.H.M. van den, Dijk, L. van, Bos, J.M., Kramers, C., Bemt, B.J.F. van den. Communication about Drug-Related Problems (DRPs) during patients' visits to Dutch physicians and pharmacies. Health Communication: 2020, 35(2), p. 201-208

overs. Patient safety solutions. Retrieved from www.who.int/patientsafety/solutions/patientsafety/PSSolution3.pdf ). Adequate communication between patients and healthcare practitioners (HCPs) is a process involving the building of a relationship, gathering information, understanding the patient's viewpoint, supplying information and decision-making (Matusitz \& Spear, 2015 Matusitz, J., \& Spear, J. (2015). Doctor-patient communication styles: A comparison between the United States and three Asian countries. Journal Of Human Behavior In The Social Environment, 25(8), 871-884. doi:10.1080/10911359.2015.1035148[Taylor \& Francis Online], , ). These different aspects of the interaction between the healthcare provider and the patient are grounded in various theoretical frameworks (Bajcar, Kennie, \& Einarson, 2005 Bajcar, J. M., Kennie, N., \& Einarson, T. R. (2005). Collaborative medication management in a team-based primary care practice: An explanatory conceptual framework. Research in Social \& Administrative Pharmacy, 1(3), 408-429. doi:10.1016/j.sapharm.2005.06.003 , , ; Feldman-Stewart, Brundage, \& Tishelman, 2005 FeldmanStewart, D., Brundage, M. D., \& Tishelman, C. (2005). A conceptual framework for patient-professional communication: An application to the cancer context. Psycho-Oncology, 14(10), 801-809. doi:10.1002/pon.950, , ).

Thus, communication about DRPs with patients should be improved. In order to find strategies to improve this communication, more information is necessary. Although communication about medication has been the subject of many published studies, these studies often only used indirect measures to evaluate the communication between patient and HCP. In several studies, the information was reported by the patient (barriers to participation in medical consultations) and was not gathered by means of a direct observation of the patient-HCP communication during visits (Gandhi et al., 2003 Gandhi, T. K., Weingart, S. N., Borus, J., Seger, A. C., Peterson, J., Burdick, E., ... Bates, D. W. (2003). Adverse drug events in ambulatory care. The New England Journal of Medicine, 348(16), 1556-1564. doi:10.1056/NEJMsa020703, Henselmans et al., 2015 Henselmans, I., Heijmans, M., Rademakers, J., \& van Dulmen, S. (2015). Participation of chronic patients in medical consultations: Patients' perceived efficacy, barriers and interest in support. Health Expectations, 18(6), 2375-2388. doi:10.1111/hex.12206, ). Studies that actually examined communication about medication by direct observation of the HCP-patient communication often focussed on communication skills and style rather than on content (Koster et al., 2015 Koster, E. S., van Meeteren, M. M., van Dijk, M., van de Bemt, B. J., Ensing, H. T., Bouvy, M. L., ... van Dijk, L. (2015). Patient-provider interaction during medication encounters: A study in outpatient pharmacies in the Netherlands. Patient Education and Counseling, 98(7), 843-848. doi:10.1016/j.pec.2015.03.007 , ; Richard \& Lussier, 2006 Richard, C., \& Lussier, M. T. (2006). MEDICODE: An instrument to describe and evaluate exchanges on medications that occur during medical encounters. Patient Education and Counseling, 64(1-3), 197-206. doi:10.1016/j.pec.2006.02.002, ). Communication about DRPs during clinical consults is rarely assessed. Consequently, little information (based on direct observation) exists on the number and type of DRPs raised and not raised during patients' visits to the HCP, by both the patient and the HCP, and the extent to which the DRPs raised are actually discussed between patients and HCPs.

Therefore, this quantitative study aims to make an inventory of the number and type of DRPs (1) raised and discussed, (2) raised but not discussed, or (3) not even raised during patients' visits to HCPs. The results of this study can be used to develop strategies to optimize communication about DRPs.

\section{Methods}

\section{Design and setting}

This quantitative cross-sectional study was conducted between September 27 and December 19, 2013 in four clinics (three surgical, one non-surgical; both academic and teaching hospitals), two general practices, and five pharmacies (community and outpatient) in the Nijmegen area, the Netherlands. 
Huiskes, V.J.B., Cramer-van der Welle, C., Ende, C.H.M. van den, Dijk, L. van, Bos, J.M., Kramers, C., Bemt, B.J.F. van den. Communication about Drug-Related Problems (DRPs) during patients' visits to Dutch physicians and pharmacies. Health Communication: 2020, 35(2), p. 201-208

\section{Selection of health practitioners}

In order to obtain a diverse sample of HCPs that communicate with patients about DRPs, we identified core characteristics of a variety of HCPs (e.g. surgical/non-surgical, primary care/secondary care, academic/teaching, physicians/pharmacists, etc.). Based on these characteristics, we created a sampling frame of practitioners in one region in the Netherlands (Nijmegen) and at least two HCPs per profession were approached to participate in the study.

\section{Patient inclusion and measurements}

\section{Inclusion}

All consecutive patients visiting the HCP (physician/pharmacist or pharmacy technician) during a regular visit on an observation day were eligible. Patients were included after obtaining verbal consent. There were no exclusion criteria, consequently patients without medication use were also included.

\section{Observation during the visits}

Each visit was observed by one and the same student. The student was trained to observe and report all communication about DRPs on the basis of a standardized observation scheme and data collection form (see Supplementary File 1). One of the researchers (CC) audited the first observations by the student and provided the student with feedback. Verbal cues from patients and HCPs indicating DRPs were inventoried by the observer during patients' visits to the HCPs, irrespective of the type of DRP or the relation of the DRP to the type of visit. Everything that a patient or a doctor said about problems or lack of clarity regarding the medication (use) counted as a cue about (a) DRPs. All these cues about DRPs were defined as DRPs raised during the visits and were reported descriptively. Subsequently it was observed whether these raised DRPs were discussed between the patient and the HCP or not. If the HCP and/or patient responded to the cue, then this was defined as a discussed DRP.

\section{Measurements after the visits}

We conducted post-encounter interviews (HCPs) and distributed post-encounter questionnaires (patient) to identify DRPs not raised by HCPs and/or patients. In the 11-item questionnaire (in Dutch), patients were also asked to report their actual prescription and over-the-counter medication use and socio-demographic data (age and gender). Patients were asked to fill out the questionnaire and to send it back to the researcher by post. Both the observations and the questionnaires were coded with the same number to match them afterwards. A schematic representation of the data collection and outcome measures is outlined in Figure 1.

\section{Outcome measures}

Main outcome measures were the number and type of DRPs raised during the visits, the number and type of raised DRPs that were subsequently discussed and the number and type of DRPs not raised during the visits by HCPs and patients.

All the DRPs were classified using the DOCUMENT classification system (Williams, Peterson, Tenni, Bindoff, \& Stafford, 2012 Williams, M., Peterson, G. M., Tenni, P. C., Bindoff, I. K., \& Stafford, A. C. (2012). DOCUMENT: A system for classifying drug-related problems in community pharmacy. International Journal of Clinical Pharmacy, 34(1), 43-52. doi:10.1007/s11096-011-9583-1 , ), with modifications as described by Kwint et al (Kwint, Faber, Gussekloo, \& Bouvy, 2011 Kwint, H. F., Faber, A., Gussekloo, J., \& Bouvy, M. L. (2011). Effects of medication review on drug-related problems in patients using automated drug-dispensing systems: A pragmatic randomized controlled study. Drugs \& aging, 28(4), 305-314. doi:10.2165/11586850-000000000-00000 , ). The DOCUMENT classification system encompasses eight main types of DRPs (Drug selection, Over-/underdose prescribed, Compliance, Untreated indications, Monitoring, Education or information, Non-clinical and Toxicity or 
Huiskes, V.J.B., Cramer-van der Welle, C., Ende, C.H.M. van den, Dijk, L. van, Bos, J.M., Kramers, C., Bemt, B.J.F. van den. Communication about Drug-Related Problems (DRPs) during patients' visits to Dutch physicians and pharmacies. Health Communication: 2020, 35(2), p. 201-208

adverse reaction) with corresponding subtypes to further classify the DRPs (Kwint, $2013 \mathrm{Kwint}, \mathrm{H}$. F. (2013). Improving appropriate medication use for older people in primary care (Doctoral dissertation). Retrieved from https://dspace.library.uu.nl/bitstream/handle/1874/276389/kwint.pdf?sequence=1. ). DRPs were coded (using the subtypes of the DOCUMENT classification system) independently by two researchers (CC-BvdB). Discrepancies in coding were discussed in order to reach consensus (CC-BvdB) about the final classification. A third investigator (CK) verified the coding.

Data analysis

Data were analyzed using STATA version 13. Descriptive statistics were provided using (weighted) mean $( \pm S D$ ) or median (p25-p75) values depending on the (non-) parametric distribution of measured variables. The weights used to calculate the weighted mean $(S D)$ were defined as 1 divided by the number of patients per type of HCPs.

\section{Results}

\section{Sample characteristics}

In total, 431 patients were included in this study during a single visit to the HCP (Table 1). These patients were observed while visiting eight GPs (18.3\%), five surgical specialists (17.4\%), seven nonsurgical specialists (18.3\%), three community pharmacy staff members $(22.7 \%)$ and two outpatient pharmacy staff members (23.2\%). Of all included patients, $385(89.3 \%)$ received a questionnaire, the remaining $46(10.7 \%)$ did not receive the questionnaire or refused to accept the questionnaire after the visit for various reasons. Finally, $176(40.8 \%)$ of the observed patients (mean age 55.8 (SD: 15.8) years; $59.7 \%$ female) returned a completed questionnaire (Table 1 ).

\section{Drug-related problems raised during patients' visits to the HCP}

In the study population, 182 (42.2\%) patients had at least one DRP raised during their visit, resulting in a weighted mean number of $0.7(S D \pm 1.1)$ DRPs raised per observed patient. In patients with at least one DRP raised during their visit, the weighted mean number of DRPs raised per patient was 1.7 $(S D \pm 1.5)$ (Table 2). DRPs were most frequently raised during patients' visits to non-surgical medical specialists followed by the outpatient pharmacy, the community pharmacy, the general practitioner and the surgical medical specialist.

Figure 2 provides the number and type of the DRPs raised during patient's visits to the medical specialist, GP or pharmacy, coded according to the DOCUMENT classification system. Overall, the most common type of DRP was non-clinical (34.1\%), which covers problems related to administrative aspects of the prescription. Other DRPs commonly raised were related to education or information (26.7\%, mainly patient information requests) and toxicity and adverse reactions (13.5\%).

Patients visiting non-surgical medical specialists were particularly found to experience DRPs about education or information (32.5\%) and toxicity and adverse reactions (21.4\%). These are also the types of DRPs most frequently raised during visits to general practitioners ( $35.7 \%$ and $23.8 \%$, respectively) and surgical medical specialists ( $27.3 \%$ and $22.7 \%$, respectively), whereas DRPs about toxicity and adverse reactions are rarely raised during the pharmacy visits (1.5\%). The DRPs most frequently raised during visits to the pharmacy were non-clinical DRPs (60.0\%) followed by DRPs about education or information (18.5\%) and drug selection (11.5\%).

Discussion between the patients and the HCPs about the DRPs raised during the visits A total of 311 DRPs were raised by $182(42.2 \%)$ of the observed patients. In total, $255(82 \%)$ of these DRPs were subsequently discussed between the patient and the HCP. This occurred in $88.5 \%$ of the 182 visits in which one or more of these DRPs were raised. Details on the distribution by HCP are depicted in Table 2. 
Huiskes, V.J.B., Cramer-van der Welle, C., Ende, C.H.M. van den, Dijk, L. van, Bos, J.M., Kramers, C., Bemt, B.J.F. van den. Communication about Drug-Related Problems (DRPs) during patients' visits to Dutch physicians and pharmacies. Health Communication: 2020, 35(2), p. 201-208

DRPs raised during the visits and actually discussed between the patient and the HCP The 255 raised DRPs that were actually discussed between HCPs and patients were most frequently of the type non-clinical (32.2\%) and education or information (30.6\%). Details on the proportions of DRPs discussed between patient and HCP per type of DRP are outlined in Figure 3.

\section{DRPs raised during the visits and not discussed between the patient and the HCP}

The 50 raised DRPs that were not discussed between HCPs and patients mostly concerned non-clinical issues $(46.0 \%)$ and toxicity or adverse reactions (18.0\%).

The types of DRPs that were raised during visits and that were relatively most often not discussed (in more than $20 \%$ of the cases of that type of DRP) concerned compliance (not discussed in 14 (27.3\%) of the cases), untreated indications (15 (28.6\%)), non-clinical issues (82 $(22.6 \%))$ and toxicity or adverse reactions $(33(21.4 \%))$.

\section{DRPs not raised during patients' visits by both HCPs and patients}

\section{DRPs not raised by patients}

Eleven patients reported DRPs that had not been raised during their visits. These were reported in questionnaires after a visit to the medical specialist $(n=4)$, the GP $(n=4)$ and the pharmacy $(n=3)$, respectively. These DRPs that had not been raised during the visits were problems concerning education or information (36.4\%), compliance (27.3\%), drug selection (18.2\%) and toxicity or adverse reactions (18.2\%). No DRPs at all were raised during $72 \%$ of the visits of these patients. Reasons for not raising DRPs from the patients' point of view were: "forgot to mention the DRP during the visit" (54.5\%), "no idea why not discussed" (18.2\%), "HCP did not take problems seriously" (9.1\%), "HCP is not really listening to their problems due to lack of time" (9.1\%) and no reason (9.1\%).

\section{DRPs not raised by HCPs}

HCPs reported 17 visits during which DRPs had not been raised. These were reported in interviews with medical specialists $(n=11)$ and GPs $(n=6)$, respectively. HCPs stated that DRPs that had not been raised concerned compliance (23.5\%), non-clinical issues (17.6\%), mainly incomplete medication records), toxicity or adverse reactions (17.6\%), untreated indications (11.8\%), drug selection (11.8\%), and education or information (11.8\%) and $5.8 \%$ was not classifiable. No DRPs at all were raised during $47.1 \%$ of the visits of these patients.

HCPs reported "lack of time" (23.5\%), "too much information/changes at once" (23.5\%) and "not necessary/useful" (17.6\%) as main reasons for not raising DRPs. In the other $35.3 \%$ of the cases, various reasons for not raising the DRP were reported.

There was hardly any overlap between the visits for which patients and HCPs reported DRPs that had not been raised during the visits. There was only one visit after which both the patient and the HCP reported a DRP that had not been raised. However, the DRP that had not been raised by the patient was different from the DRP that had not been raised by the HCP.

\section{Discussion and conclusion}

\section{Discussion}

To our knowledge, this is the first study examining the extent of communication about DRPs by directly observing the communication during patients' visits to the physician and the pharmacy. DRPs were often (in $42 \%$ of the visits) raised during patient-HCP interactions. The most DRPs per visit were raised during encounters with a non-surgical specialist (mostly with respect to education or information and toxicity or adverse reactions) and pharmacy staff members (predominantly about nonclinical questions and education or information). That DRPs are more often raised during consults with 
Huiskes, V.J.B., Cramer-van der Welle, C., Ende, C.H.M. van den, Dijk, L. van, Bos, J.M., Kramers, C., Bemt, B.J.F. van den. Communication about Drug-Related Problems (DRPs) during patients' visits to Dutch physicians and pharmacies. Health Communication: 2020, 35(2), p. 201-208

non-surgical specialists and pharmacy staff members might be caused by (1) the difference in the degree of focus on pharmacotherapy between the various HCPs and (2) the selection of patients. Both non-surgical specialists and pharmacy staff members are professionals who are mainly focused on medication and the interventions that they apply usually relate to drug therapy. Furthermore, nonsurgical specialists probably see more patients that use high-risk and/or larger number of medications than surgical specialists and general practitioners.

However, these raised DRPs are not always discussed between patients and HCPs. In almost $12 \%$ of the patient visits in which DRPs were raised, at least one DRP was not discussed with the patient. A total of $16 \%$ of the DRPs raised were not discussed. The types of DRPs raised during visits that were discussed relatively less often were about compliance, untreated indications, non-clinical issues and toxicity or adverse reactions. Possibly because these types of DRPs are judged to be (1) more sensitive and time-consuming to discuss, (2) less urgent to intervene on immediately, (3) less important and/or (4) difficult to solve. Despite aforementioned reasons, not discussing DRPs (particularly in the category toxicity or adverse reactions, compliance and undertreatment) may possibly result in negative treatment outcomes.

Furthermore, both HCPs and patients reported existing DRPs that had not been raised at all during 4$6 \%$ of the visits. There was hardly any overlap between the visits for which patients and HCPs reported DRPs that had not been raised during the visits. This might be explained by the different priorities and expectations that HCPs and patients have during medical consultations (Voigt, Wrede, DiederichsEgidi, Dierks, \& Junius-Walker, 2010 Voigt, I., Wrede, J., Diederichs-Egidi, H., Dierks, M. L., \& JuniusWalker, U. (2010). Priority setting in general practice: Health priorities of older patients differ from treatment priorities of their physicians. Croatian Medical Journal, 51(6), 483-492._, _). Furthermore, the reasons for not mentioning DRPs differed among patients and HCPs. HCPs reported "lack of time" and "too much information/changes at once" and patients "forgot to mention" as reasons for not raising the DRPs during the visit. Possible solutions for these barriers might be to have both HCPs and patients be better prepared for the visit, prioritization of the issues to be discussed and alignment of the visit agendas at the start of the visit (Kowalski et al., 2018 Kowalski, C. P., McQuillan, D. B., Chawla, N., Lyles, C., Altschuler, A., Uratsu, C. S., ... Grant, R. W. (2018). 'The hand on the doorknob': Visit agenda setting by complex patients and their primary care physicians. Journal of the American Board of Family Medicine, 31(1), 29-37. doi:10.3122/jabfm.2018.01.170167_, ; Robinson, Tate, \& Heritage, 2016 Robinson, J. D., Tate, A., \& Heritage, J. (2016). Agenda-setting revisited: When and how do primary-care physicians solicit patients' additional concerns? Patient Education and Counseling, 99(5), 718-723. doi:10.1016/j.pec.2015.12.009_, _).

It is conceivable that better communication between HCP and patient improves the patient's understanding of drug treatment, shared decision making and patient's medication adherence. The clinical impact of enhanced patient-HCP communication about DRPs is, for example, illustrated by studies that show improved blood pressure control due to additional adherence communication between HCP and patient (Blenkinsopp, Phelan, Bourne, \& Dakhil, 2000 Blenkinsopp, A., Phelan, M., Bourne, J., \& Dakhil, N. (2000). Extended adherence support by community pharmacists for patients with hypertension: A randomised controlled trial. International Journal of Clinical Pharmacy, 8, 3175. _; Solomon et al., 1998 Solomon, D. K., Portner, T. S., Bass, G. E., Gourley, D. R., Gourley, G. A., Holt, J. M., ... Lawrence, B. L. (1998). Clinical and economic outcomes in the hypertension and COPD arms of a multicenter outcomes study. Journal of the American Pharmaceutical Association (Washington,D.C.: 1996), 38(5), 574-585., , _). Furthermore, research on medication review showed that DRPs that were identified during patient interviews were more clinically relevant than DRPs based on medical records only (Kwint, Faber, Gussekloo, \& Bouvy, 2012 Kwint, H. F., Faber, A., Gussekloo, J., \& Bouvy, M. L. (2012). The contribution of patient interviews to the identification of drug-related problems in home medication review. Journal of Clinical Pharmacy and Therapeutics, 37(6), 674-680. doi:10.1111/j.1365-2710.2012.01370.x_, _). Studies on non drug-related patient-HCP communication also indicated that effective $\mathrm{HCP}-$ patient communication may directly impact patient health outcomes 
Huiskes, V.J.B., Cramer-van der Welle, C., Ende, C.H.M. van den, Dijk, L. van, Bos, J.M., Kramers, C., Bemt, B.J.F. van den. Communication about Drug-Related Problems (DRPs) during patients' visits to Dutch physicians and pharmacies. Health Communication: 2020, 35(2), p. 201-208

(Stewart, 1995 Stewart, M. A. (1995). Effective physician-patient communication and health outcomes: A review. Canadian Medical Association Journal, 152(9), 1423-1433.,, , ,; Street, 2013 Street, R. L., Jr. (2013). How clinician-patient communication contributes to health improvement: Modeling pathways from talk to outcome. Patient Education and Counseling, 92(3), 286-291.

doi:10.1016/j.pec.2013.05.004__ ). Based on these studies, one might assume that more effective patient-HCP communication about DRPs will lead to increased patient knowledge, patient involvement and possibly better pharmacotherapy and health outcomes as well.

In this study, only existing DRPs spontaneously raised during the visits or reported in questionnaires/interviews after the visit were assessed. Physicians and pharmacy staff members did not actively ask or screen for DRPs. Consequently, the weighted mean number of DRPs per patient reported in this study $(0.7 S D \pm 1.1)$ is lower than the average number of four DRPs per patient reported in medication review trials, as the main goal during medication review trials (often including patients with polypharmacy) is to identify DRPs. Other explanations for the relatively low number of DRPs might be that (a) patients without medication were not excluded and that (b) issues other than DRPs were more important for patients to discuss with the HCP. Furthermore, there may have been an information bias due to the presence of the observer in the consulting room.

Concerning the existing DRPs not even raised during the consults on the one hand, the reported number of DRPs not raised by both patients and HCPs might be an underestimation, as these were collected in response to a single question, instead of by an in-depth exploration using a list with different DRP categories, for example. This may implicate that the need for communication between HCPs and patients about DRPs is even greater. On the other hand, the reported number of existing DRPs not raised by patients might be an overestimation due to selection bias, as patients that actually encounter DRPs were possibly more willing to fill out the questionnaire.

Existing DRPs (noticed by the HCP or encountered by the patient) were not raised by HCPs in $3.9 \%$ and by patients in $6.3 \%$ of the consultations. Although these percentages seem to be relatively low, these percentages represent large absolute numbers. In the Netherlands, for example, 30 million patients visit the outpatient clinic yearly (Stichting Dutch Hospital Data, 2016 Stichting Dutch Hospital Data. (2016). Kengetallen nederlandse ziekenhuizen 2014 [Dutch hospital data 2014]. Retrieved from www.nvz-ziekenhuizen.nl/_library/33659/RapportageKengetallen2014.pdf ). Taking these data into account, HCPs and patients do not raise and consequently do not communicate about at least one existing DRP during 7200 and 8400 visits every day, respectively.

The objective of this study was to assess the communication between a diverse sample of HCPs and patients about DRPs. Therefore, the communication between HCP and patients about DRPs was assessed in several primary- and secondary care settings with a large variety in HCPs. Although this variety yields a greater spread, it improves the generalizability to different HCPs with respect to the communication between HCP and patient about DRPs.

\section{Conclusion}

HCPs and patients should be aware that, although DRPs are often raised during clinical consultations, almost one in six DRPs raised are not discussed between HCP and patient. Furthermore, HCPs and patients should realize that during $4-6 \%$ of the visits at least one DRP is not raised at all by HCPs and/or patients. As this might hamper patients' safety, further research is necessary (1) to find strategies/tools to enhance communication about DRPs and (2) to examine the impact of better communication about DRPs. Examples of these strategies encompass to have HCPs and patients be better prepared for the visit, prioritization of the issues and alignment of the visit agendas (Kowalski et al., 2018 Kowalski, C. P., McQuillan, D. B., Chawla, N., Lyles, C., Altschuler, A., Uratsu, C. S., ... Grant, R. W. (2018). 'The hand on the doorknob': Visit agenda setting by complex patients and their primary care physicians. Journal of the American Board of Family Medicine, 31(1), 29-37. doi:10.3122/jabfm.2018.01.170167_, _; Robinson et al., 2016 Robinson, J. D., Tate, A., \& Heritage, J. (2016). Agenda-setting revisited: When and how do primary-care physicians solicit patients' additional 
Huiskes, V.J.B., Cramer-van der Welle, C., Ende, C.H.M. van den, Dijk, L. van, Bos, J.M., Kramers, C., Bemt, B.J.F. van den. Communication about Drug-Related Problems (DRPs) during patients' visits to Dutch physicians and pharmacies. Health Communication: 2020, 35(2), p. 201-208

concerns? Patient Education and Counseling, 99(5), 718-723. doi:10.1016/j.pec.2015.12.009,_) and careful listening, explorative communication and tailoring the communication to the individual needs and situation of the patient (Matusitz \& Spear, 2014 Matusitz, J., \& Spear, J. (2014). Effective doctorpatient communication: An updated examination. Social Work in Public Health, 29(3), 252-266. doi:10.1080/19371918.2013.776416).

\section{Acknowledgments}

The authors like to acknowledge Thien Pham for his contribution in performing the main part of the observations. Furthermore, we like to thank all participating pharmacies, medical specialists and general practitioners.

\section{References}

1. American Pharmacists Association and National Association of Chain Drug Stores Foundation. (2016). Medication therapy management in pharmacy practice. Core elements of an MTM service model. Retrieved from www.pharmacist.com/sites/default/files/files/core elements of an $\mathrm{mtm}$ practice.pdf

2. Australian Commission on Safety and Quality in Health Care. (2016). The OSSIE guide to clinical handover improvement. Retrieved from www.safetyandquality.gov.au/wpcontent/uploads/2012/01/ossie.pdf

3. Bajcar, J. M., Kennie, N., \& Einarson, T. R. (2005). Collaborative medication management in a team-based primary care practice: An explanatory conceptual framework. Research in Social \& Administrative Pharmacy, 1(3), 408-429. doi:10.1016/j.sapharm.2005.06.003

4. Blenkinsopp, A., Phelan, M., Bourne, J., \& Dakhil, N. (2000). Extended adherence support by community pharmacists for patients with hypertension: A randomised controlled trial. International Journal of Clinical Pharmacy, 8, 3-175.

5. Feldman-Stewart, D., Brundage, M. D., \& Tishelman, C. (2005). A conceptual framework for patient-professional communication: An application to the cancer context. PsychoOncology, 14(10), 801-809. doi:10.1002/pon.950

6. Gandhi, T. K., Weingart, S. N., Borus, J., Seger, A. C., Peterson, J., Burdick, E., ... Bates, D. W. (2003). Adverse drug events in ambulatory care. The New England Journal of Medicine, 348(16), 1556-1564. doi:10.1056/NEJMsa020703

7. Henselmans, I., Heijmans, M., Rademakers, J., \& van Dulmen, S. (2015). Participation of chronic patients in medical consultations: Patients' perceived efficacy, barriers and interest in support. Health Expectations, 18(6), 2375-2388. doi:10.1111/hex.12206

8. Howard, R., Avery, A., \& Bissell, P. (2008). Causes of preventable drug-related hospital admissions: A qualitative study. Quality \& Safety in Health Care, 17(2), 109-116. doi:10.1136/qshc.2007.022681

9. Koster, E. S., van Meeteren, M. M., van Dijk, M., van de Bemt, B. J., Ensing, H. T., Bouvy, M. L., ... van Dijk, L. (2015). Patient-provider interaction during medication encounters: A study in outpatient pharmacies in the Netherlands. Patient Education and Counseling, 98(7), 843-848. doi:10.1016/j.pec.2015.03.007

10. Kowalski, C. P., McQuillan, D. B., Chawla, N., Lyles, C., Altschuler, A., Uratsu, C. S., ... Grant, R. W. (2018). 'The hand on the doorknob': Visit agenda setting by complex patients and their primary care physicians. Journal of the American Board of Family Medicine, 31(1), 29-37. doi:10.3122/jabfm.2018.01.170167

11. Kwint, H. F. (2013). Improving appropriate medication use for older people in primary care (Doctoral dissertation). Retrieved from https://dspace.library.uu.nl/bitstream/handle/1874/276389/kwint.pdf? sequence=1 . 
Huiskes, V.J.B., Cramer-van der Welle, C., Ende, C.H.M. van den, Dijk, L. van, Bos, J.M., Kramers, C., Bemt, B.J.F. van den. Communication about Drug-Related Problems (DRPs) during patients' visits to Dutch physicians and pharmacies. Health Communication: 2020, 35(2), p. 201-208

12. Kwint, H. F., Faber, A., Gussekloo, J., \& Bouvy, M. L. (2011). Effects of medication review on drug-related problems in patients using automated drug-dispensing systems: A pragmatic randomized controlled study. Drugs \& aging, 28(4), 305-314. doi:10.2165/11586850-000000000-00000

13. Kwint, H. F., Faber, A., Gussekloo, J., \& Bouvy, M. L. (2012). The contribution of patient interviews to the identification of drug-related problems in home medication review. Journal of Clinical Pharmacy and Therapeutics, 37(6), 674-680. doi:10.1111/j.13652710.2012.01370.x

14. Leendertse, A. J., Egberts, A. C., Stoker, L. J., \& van den Bemt, P. M. (2008). Frequency of and risk factors for preventable medication-related hospital admissions in the Netherlands. Archives of Internal Medicine, 168(17), 1890-1896. doi:10.1001/archinternmed.2008.3

15. Matusitz, J., \& Spear, J. (2014). Effective doctor-patient communication: An updated examination. Social Work in Public Health, 29(3), 252-266. doi:10.1080/19371918.2013.776416

16. [Taylor \& Francis Online],

17. Matusitz, J., \& Spear, J. (2015). Doctor-patient communication styles: A comparison between the United States and three Asian countries. Journal Of Human Behavior In The Social Environment, 25(8), 871-884. doi:10.1080/10911359.2015.1035148

18. [Taylor \& Francis Online],

19. Patient-Centered Primary Care Collaborative. (2016). PCPCC medication management task force. integrating comprehensive medication management to optimize patient outcomes. Retrieved from www.pcpcc.org/sites/default/files/media/medmanagement.pdf

20. Pharmaceutical Care Network Europe Foundation. (2016). The PCNE classification V 6.2. Retrieved from www.pcne.org/upload/files/11 PCNE classification V6-2.pdf

21. Prins, M., Schoen, T., Doggen, C., van Dijk, L., \& van Dulmen, S. (2008). Het betrekken van het perspectief van patiënt en voorschrijver bij het verbeteren van de communicatie over geneesmiddelen en therapietrouw [Involving the perspective of patient and prescriber in improving communication about medicines and adherence]. Retrieved from www.nivel.nl/sites/default/files/bestanden/NIVW\%2019.pdf

22. Richard, C., \& Lussier, M. T. (2006). MEDICODE: An instrument to describe and evaluate exchanges on medications that occur during medical encounters. Patient Education and Counseling, 64(1-3), 197-206. doi:10.1016/j.pec.2006.02.002

23. Robinson, J. D., Tate, A., \& Heritage, J. (2016). Agenda-setting revisited: When and how do primary-care physicians solicit patients' additional concerns? Patient Education and Counseling, 99(5), 718-723. doi:10.1016/j.pec.2015.12.009

24. Solomon, D. K., Portner, T. S., Bass, G. E., Gourley, D. R., Gourley, G. A., Holt, J. M., ... Lawrence, B. L. (1998). Clinical and economic outcomes in the hypertension and COPD arms of a multicenter outcomes study. Journal of the American Pharmaceutical Association (Washington,D.C.: 1996), 38(5), 574-585.

25. Stewart, M. A. (1995). Effective physician-patient communication and health outcomes: A review. Canadian Medical Association Journal, 152(9), 1423-1433.

26. Stichting Dutch Hospital Data. (2016). Kengetallen nederlandse ziekenhuizen 2014 [Dutch hospital data 2014]. Retrieved from www.nvzziekenhuizen.nl/ library/33659/RapportageKengetallen2014.pdf

27. Street, R. L., Jr. (2013). How clinician-patient communication contributes to health improvement: Modeling pathways from talk to outcome. Patient Education and Counseling, 92(3), 286-291. doi:10.1016/j.pec.2013.05.004

28. van Bijnen, E., \& van Dulmen, S. (2010). Een goed gesprek over geneesmiddelgebruik; determinanten vanuit het perspectief van de voorschrijver [A good converstation about 
Huiskes, V.J.B., Cramer-van der Welle, C., Ende, C.H.M. van den, Dijk, L. van, Bos, J.M., Kramers, C., Bemt, B.J.F. van den. Communication about Drug-Related Problems (DRPs) during patients' visits to Dutch physicians and pharmacies. Health Communication: 2020, 35(2), p. 201-208

drug use; determinants from the perspective of the prescriber]. Retrieved from www.nivel.nl/sites/default/files/bestanden/Rapport-Geneesmiddelgebruik-2010.pdf

29. Voigt, I., Wrede, J., Diederichs-Egidi, H., Dierks, M. L., \& Junius-Walker, U. (2010). Priority setting in general practice: Health priorities of older patients differ from treatment priorities of their physicians. Croatian Medical Journal, 51(6), 483-492.

30. WHO Collaborating Centre for Patient Safety Solutions. (2016). Communication during patient hand-overs. Patient safety solutions. Retrieved from www.who.int/patientsafety/solutions/patientsafety/PS-Solution3.pdf

31. Williams, M., Peterson, G. M., Tenni, P. C., Bindoff, I. K., \& Stafford, A. C. (2012). DOCUMENT: A system for classifying drug-related problems in community pharmacy. International Journal of Clinical Pharmacy, 34(1), 43-52. 
Huiskes, V.J.B., Cramer-van der Welle, C., Ende, C.H.M. van den, Dijk, L. van, Bos, J.M., Kramers, C., Bemt, B.J.F. van den. Communication about Drug-Related Problems (DRPs) during patients' visits to Dutch physicians and pharmacies. Health Communication: 2020, 35(2), p. 201-208

Tables and Figures

Table 1. Number of observed patients and returned questionnaires per type of HCP.

\begin{tabular}{|c|c|c|}
\hline & $\begin{array}{l}\text { Total number of patients included, } \\
n\end{array}$ & $\| \begin{array}{l}\text { Number of returned patient questionnaires } \\
n(\%)\end{array}$ \\
\hline Medical specialist & 154 & 79 (51.3\%) \\
\hline Surgical $^{\mathrm{a}}$ & 75 & |39 (52.0\%) \\
\hline Non-surgical $^{b}$ & 79 & $40(50.6 \%)$ \\
\hline General practitioner & 79 & $29(36.7 \%)$ \\
\hline Pharmacy & 198 & $68(34.3 \%)$ \\
\hline Community & 98 & $39(39.8 \%)$ \\
\hline Outpatient & 100 & $29(29 \%)$ \\
\hline Total & 431 & 176 (40.8\%) \\
\hline
\end{tabular}

${ }^{\mathrm{a}} 35 \%$ orthopaedic surgeon, $65 \%$ other surgeon. ${ }^{\mathrm{b}} 54 \%$ internist, $46 \%$ rheumatologist.

Table 2. Number of DRPs raised and number of DRPs raised and discussed with the patient during patients' visits to the HCP.

\begin{tabular}{|c|c|c|c|c|c|c|c|}
\hline & $\begin{array}{l}\text { Number } \\
\text { of } \\
\text { patients, } \\
n\end{array}$ & $\begin{array}{l}\text { Number of } \\
\text { patients' } \\
\text { visits with } \\
\text { at least one } \\
\text { DRP during } \\
\text { visit, } \\
n(\%)\end{array}$ & \begin{tabular}{|l} 
Number \\
of DRPs \\
during \\
visits, \\
$n$
\end{tabular} & $\begin{array}{l}\text { Mean } \\
\text { number of } \\
\text { DRPs per } \\
\text { observed } \\
\text { patient, } \\
M(S D)\end{array}$ & $\mid$\begin{tabular}{|l|} 
Mean \\
Number of \\
DRPs per \\
observed \\
patient with \\
DRPs raised, \\
$M(S D)$
\end{tabular} & \begin{tabular}{|l|} 
Number of \\
visits with \\
DRPs raised \\
and discussed \\
between \\
HCPs and \\
patients, $n$ \\
(\%)
\end{tabular} & \begin{tabular}{|l} 
Number of \\
DRPs \\
discussed \\
between \\
HCPs and \\
patients, $n$ \\
(\%)
\end{tabular} \\
\hline $\begin{array}{l}\text { Medical } \\
\text { specialist }\end{array}$ & 154 & 72 (46.8\%) & 139 & $0.9(1.3)$ & $1.9(1.3)$ & 59 (81.9\%) & 105 (75.5\%) \\
\hline Surgical & 75 & $16(21.3 \%)$ & 22 & $0.3(0.7)$ & $1.4(0.8)$ & $12(75.0 \%)$ & $16(72.7 \%)$ \\
\hline $\begin{array}{c}\text { Non- } \\
\text { surgical }\end{array}$ & 79 & 56 (70.9\%) & 117 & $1.5(1.5)$ & $2.1(1.4)$ & 47 (83.9\%) & 89 (76.1\%) \\
\hline $\begin{array}{l}\text { General } \\
\text { practitioner }\end{array}$ & 79 & $24(30.4 \%)$ & 42 & $0.5(0.9)$ & $1.8(0.8)$ & 23 (95.8\%) & 37 (88.1\%) \\
\hline Pharmacy & 198 & $86(43.4 \%)$ & 130 & $0.7(1.0)$ & $1.5(1.0)$ & 79 (91.9\%) & 113 (86.9\%) \\
\hline Community & 98 & 38 (38.8\%) & 61 & $0.6(0.9)$ & $1.6(0.9)$ & 35 (92.1\%) & 54 (88.5\%) \\
\hline Outpatient & 100 & $48(48.0 \%)$ & 69 & $0.7(1.1)$ & $1.4(1.2)$ & 44 (91.7\%) & 59 (85.5\%) \\
\hline Total & 431 & $182(42.2 \%)$ & 311 & $0.7(1.1)^{\mathrm{a}}$ & $1.7(1.5)^{a}$ & $161(88.5 \%)$ & 255 (82.0\%) \\
\hline
\end{tabular}

${ }^{a}$ Weighted mean $( \pm S D)$. 
Huiskes, V.J.B., Cramer-van der Welle, C., Ende, C.H.M. van den, Dijk, L. van, Bos, J.M., Kramers, C., Bemt, B.J.F. van den. Communication about Drug-Related Problems (DRPs) during patients' visits to Dutch physicians and pharmacies. Health Communication: 2020, 35(2), p. 201-208

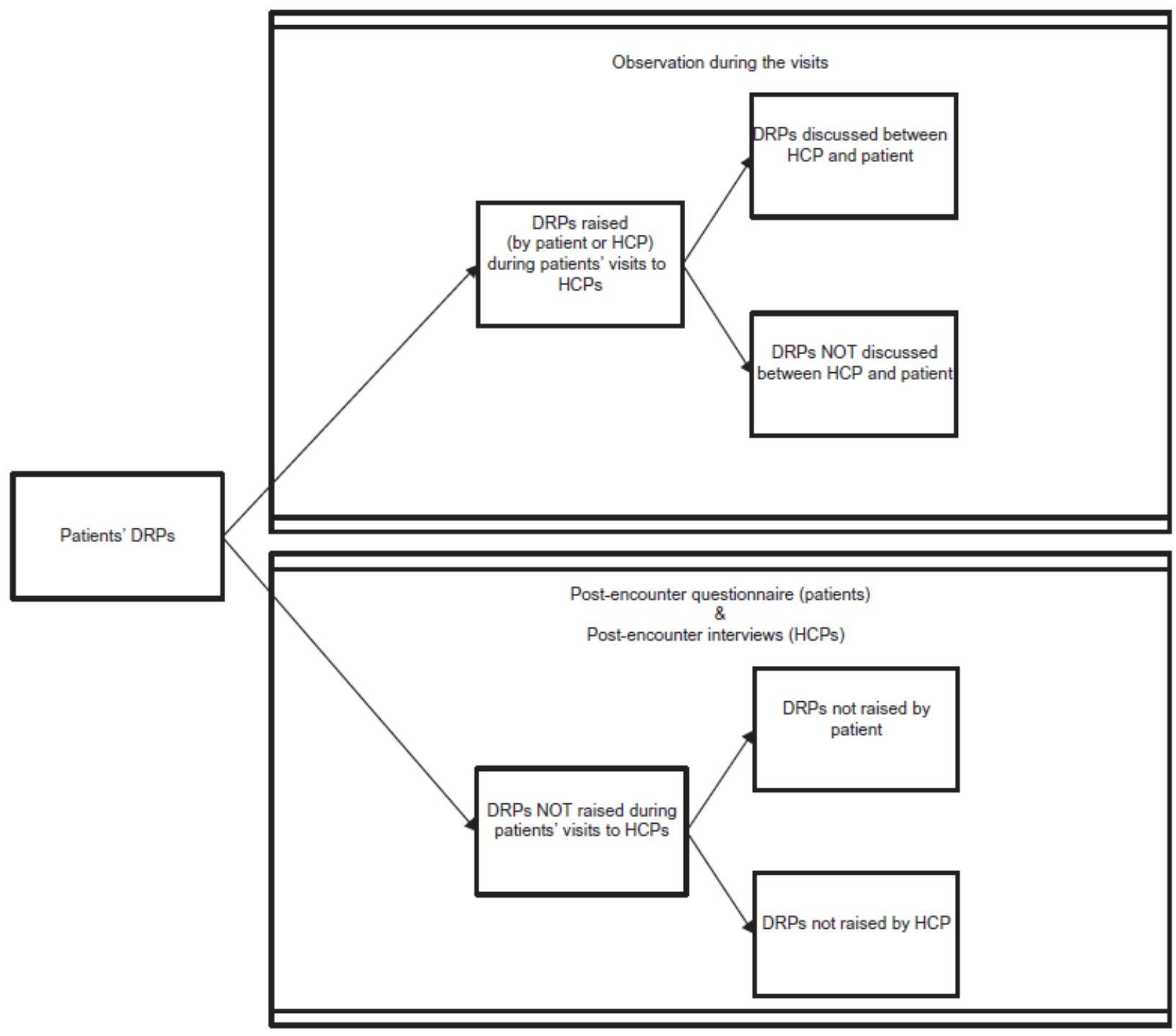

Figure 1. Schematic representation of data collection and outcome measures. DRP = drug-related problem; HCP = healthcare practitioner. 
Huiskes, V.J.B., Cramer-van der Welle, C., Ende, C.H.M. van den, Dijk, L. van, Bos, J.M., Kramers, C., Bemt, B.J.F. van den. Communication about Drug-Related Problems (DRPs) during patients' visits to Dutch physicians and pharmacies. Health Communication: 2020, 35(2), p. 201-208

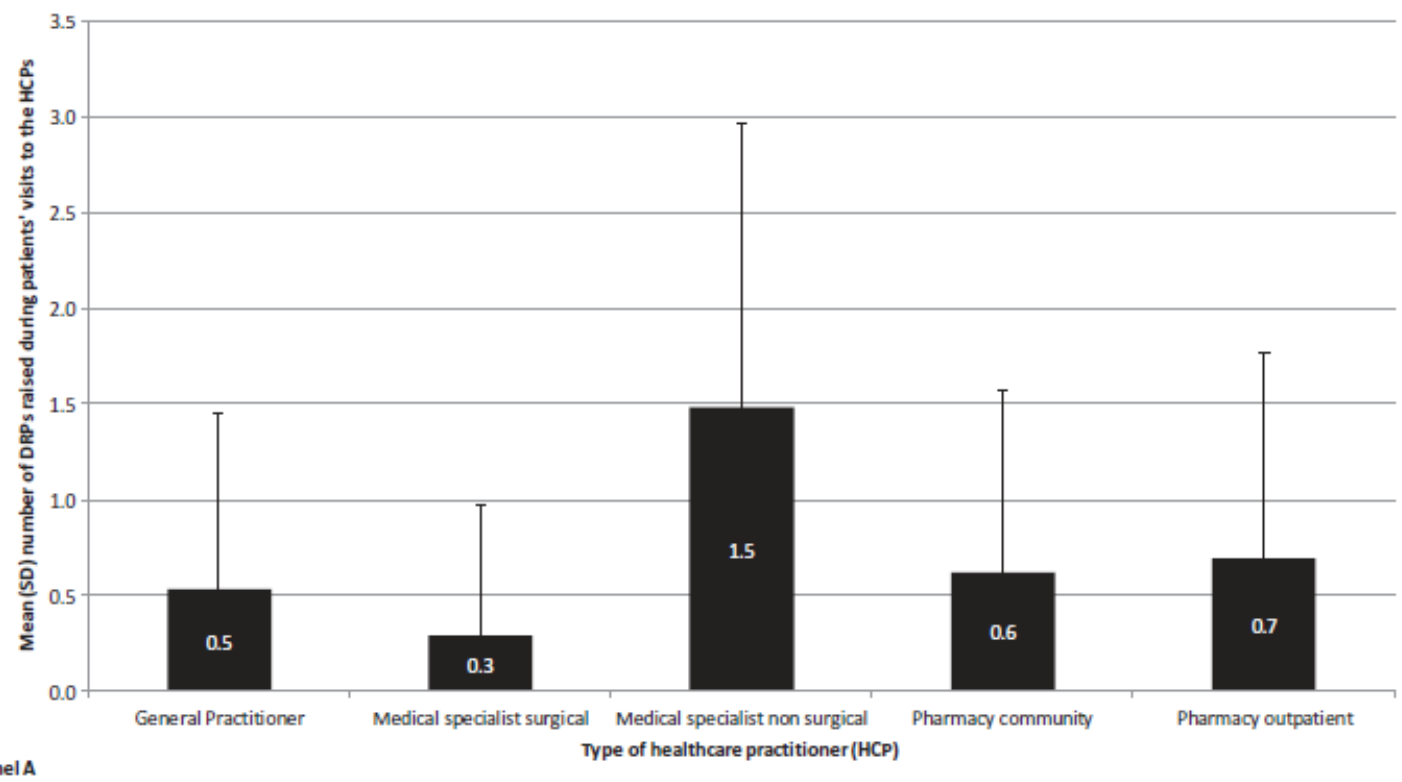

PanelA

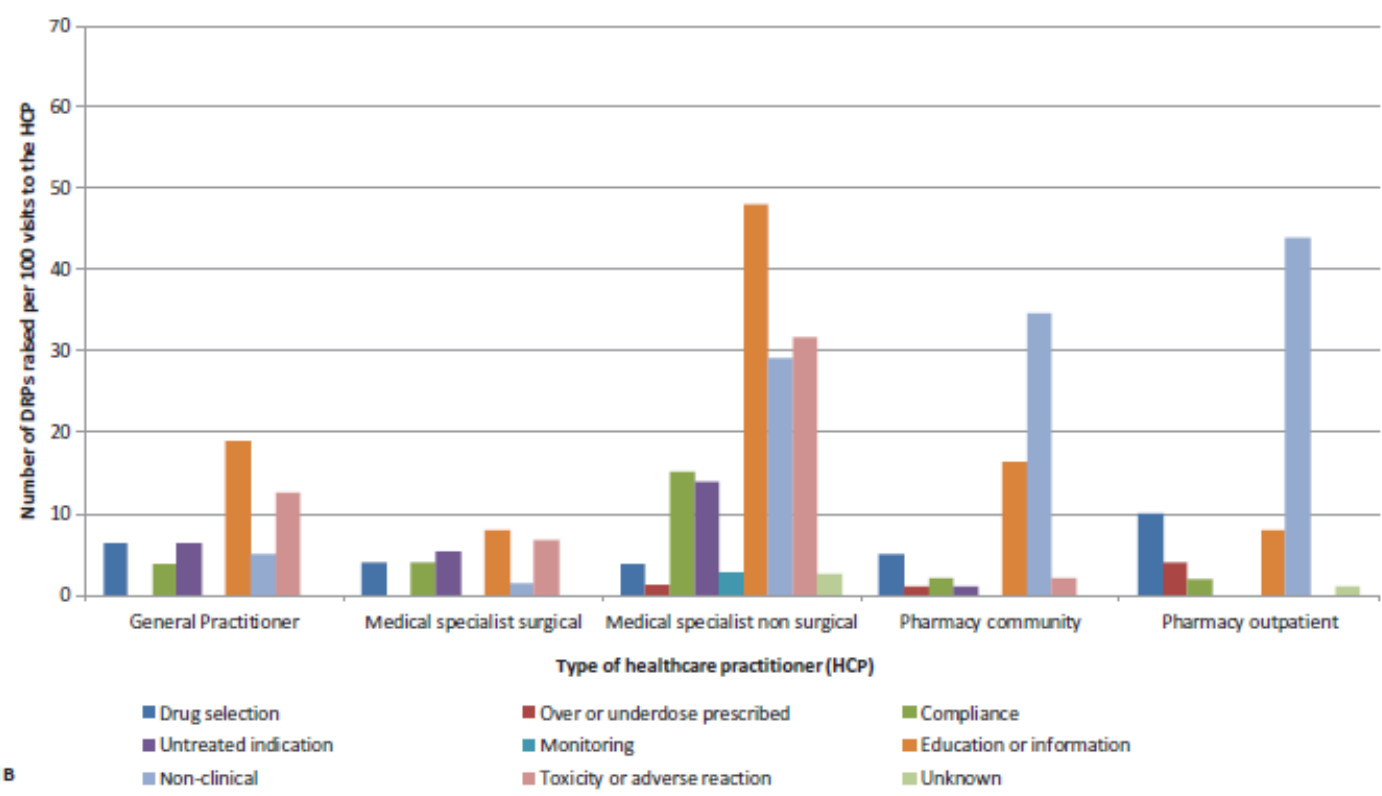

Figure 2. Distribution of DRPs raised during patients' visits to HCPs. Panel A depicts the mean (SD) number of DRPs raised per type of HCP. Panel B depicts the number DRPs raised in 100 visits per type of DRP and per type of HCP. 
Huiskes, V.J.B., Cramer-van der Welle, C., Ende, C.H.M. van den, Dijk, L. van, Bos, J.M., Kramers, C., Bemt, B.J.F. van den. Communication about Drug-Related Problems (DRPs) during patients' visits to Dutch physicians and pharmacies. Health Communication: 2020, 35(2), p. 201-208

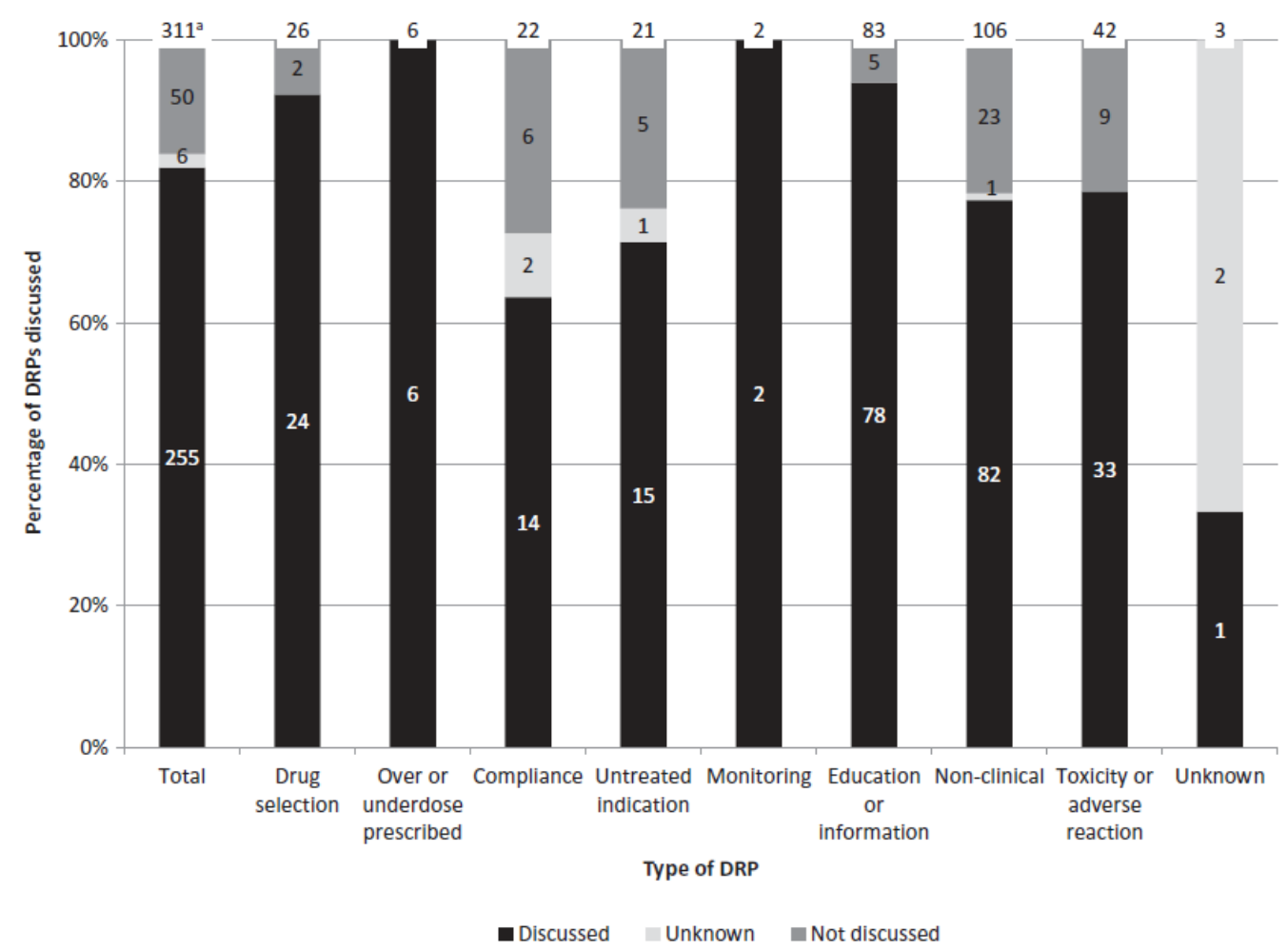

Figure 3. Proportion of DRPs discussed with the patient per type of DRP. ${ }^{a}$ Total number of DRPs per type of DRP are represented on top of the bars 


\section{Observation}

Date: .. - .. - ....

GP / medical specialist/pharmacy staff member:

Drug-related problems raised during the consult

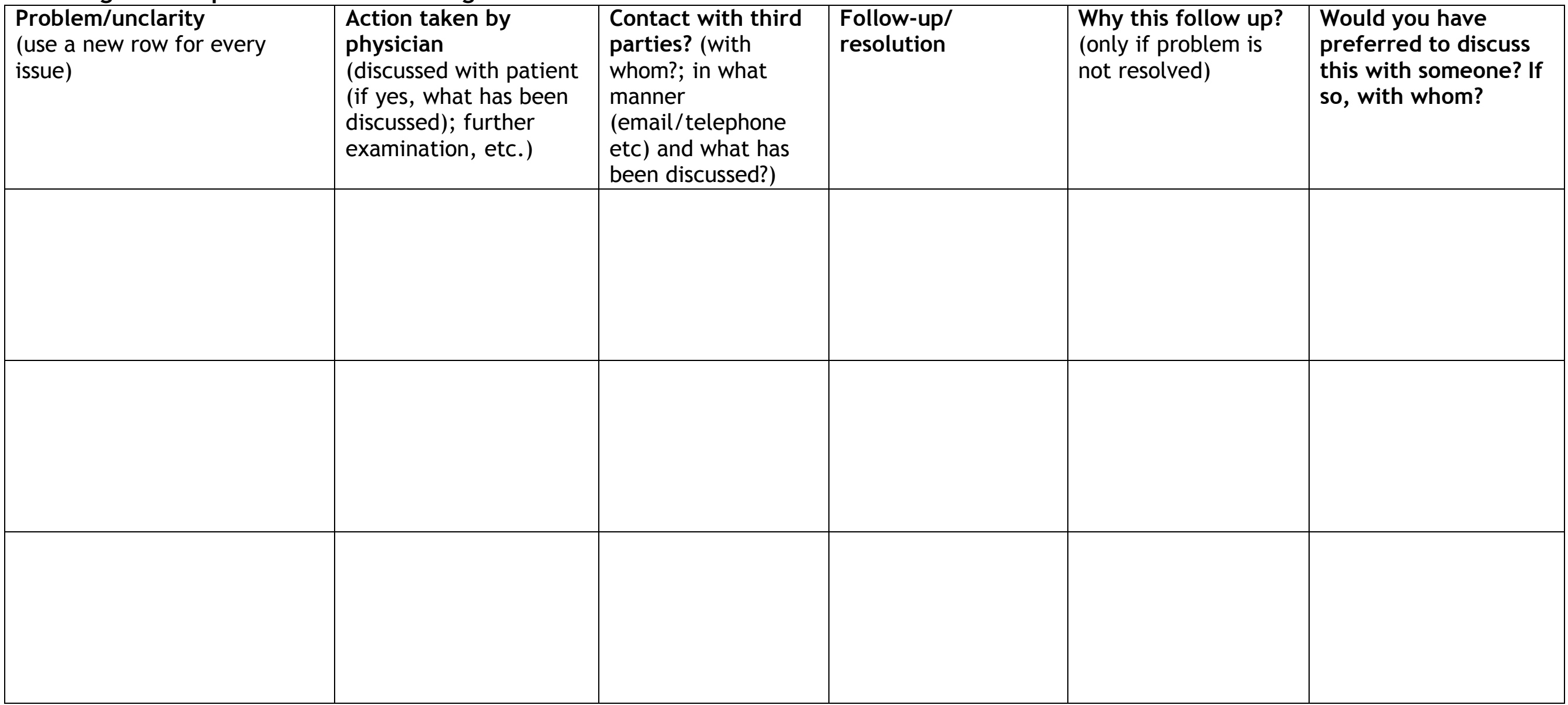


Other drug-related problems (not raised during the consult)

Discussion with healthcare practitioner after the consult: which drug-related problems have not been raised during the consult?

Problem not raised /unclarity $\quad$ Why not raised?

not raised

(use a new row for every issue)

\section{(no responsibility of the}

consulting physician, not enough

time, not enough knowledge,

etc.)
Action planned to be taken by Why this follow-up?

physician and follow-

up/solution

\begin{tabular}{|l|l|l|l|l|} 
& $\begin{array}{l}\text { time, not enough knowledge, } \\
\text { etc.) }\end{array}$ & & & \\
\hline & & & & \\
\hline & & & & \\
\hline & & & & \\
\hline & & & & \\
\hline
\end{tabular}

